Methods 216 Italian SSc patients, followed between 2006 and 2008 , were studied. Sera were tested by immunofluorescence for antinuclear antibodies, counterimmunoelectrophoresis for anti-ENA (anti-topo I, PM-Scl, Ku, U1RNP and others), and ELISA for anti-RNA polymerase III. Available sera (negative for all these) were also tested by immunoprecipitation (IP, protein analyses by 35S-methionine labelled cells; RNA analyses by urea-PAGE and silver staining). Specificities of autoantibodies were verified using reference sera. Charts were reviewed for clinical information.

Results Out of 216 patients, 67 were ACA (+) and 81 were anti-topo I (+). Among the remaining 68 patients, 15 were antiRNAP III positive. Sera from 12 anti-nucleolar staining positive samples were available for IP: anti-Th/To antibodies were found in 8 of 12 patients (67\%). They were all negative for ACA, anti-RNAP III and anti-ENA. Clinical features of eight anti-Th/To patients were compared with 67 ACA (+) patients. All except one ACA (+) patient had 1SSc. Anti-Th/To patients were younger $(p=0.0046)$, with a predominant male distribution $(p=0.004)$ versus ACA (+) group. In anti-Th/To group, alveolitis $(p=0.04)$, pericarditis $(p=0.028)$ and puffy hands $(p=0.0004)$ were more frequently detected. Both groups had low Medsger cardiopulmonary index and excellent 10-year survival.

Conclusions Anti-Th/To are common in anti-nucleolar antibody positive Italian SSc patients. Both anti-Th/To and ACA patients had $1 S S c$ with excellent prognosis. Although impairment of pulmonary function appears mild, anti-Th/To group has frequent alveolitis and pericarditis. Testing for anti-Th/To should help to subset SSc patients and to follow-up properly.

\section{A22 ANTI-TH/TO ANTIBODIES IN ITALIAN SCLERODERMA PATIENTS: CLINICAL AND IMMUNOLOGICAL CORRELATIONS AND COMPARISON WITH PATIENTS WITH ANTI-CENTROMERE ANTIBODIES}

A Ceribelli, ${ }^{1}, 2,3$ I Cavazzana, ${ }^{1}$ P Airò, ${ }^{1}$ A Tincani, ${ }^{1}$ F Franceschini, ${ }^{1}$ B A Pauley, ${ }^{2}$ E K L Chan, ${ }^{2}$ M Satoh, ${ }^{3}{ }^{1}$ Rh eumatology Unit and Chair, Spedali Civili, Brescia, Italy; ${ }^{2}$ Department of Oral Biology, University of Florida, Gainesville, USA; ${ }^{3}$ Department of Medicine, University of Florida, Gainesville, USA

\subsection{6/ard.2010.129577v}

Purpose Anti-Th/To antibodies, found in $3-5 \%$ of patients with systemic sclerosis (SSc), recognise a nucleolar 7-2/8-2 RNA-protein complex. They are associated with limited SSc (1SSc) with lung involvement and reduced survival comparing with anticentromere (ACA) (+) patients. However, clinical studies on anti-Th/To are limited due to poor availability of serological tests. The aim of our study is to compare the clinical manifestations of patients with two autoantibodies associated with 1SSc: anti-Th/To and ACA.

\begin{tabular}{llll} 
Abstract 22 & Table 1 & & \\
\hline & \multicolumn{4}{l}{ Anti-Th/To (n=8) } & Anticentromere $(\mathbf{n = 6 7 )}$ & $\mathbf{p}$ Value \\
\hline Female:male & $5: 3$ & $66: 1$ & 0.0006 \\
Mean age (years $( \pm$ SD)) & $54.5( \pm 18)$ & $66.6( \pm 10.1)$ & 0.0046 \\
$\begin{array}{l}\text { Mean disease duration } \\
\text { (years ( } \pm \text { SD)) }\end{array}$ & $8.5( \pm 6.5)$ & $8.7( \pm 5.9)$ & NS \\
Limited systemic sclerosis & $100 \%$ & $98.5 \%$ & \\
Teleangiectasia & $12.5 \%$ & $49.25 \%$ & NS \\
Puffy hands & $62.5 \%$ & $9 \%$ & 0.0484 \\
Alveolitis & $38 \%$ & $4.5 \%$ & 0.0004 \\
Pericarditis & $25 \%$ & $4.5 \%$ & 0.0435 \\
\hline
\end{tabular}

